Pacific Journal of Mathematic 


\title{
HOMOMORPHISMS OF MONO-UNARY ALGEBRAS
}

\author{
EVELYN NELSON
}

\begin{abstract}
Novotny has presented what amounts to a necessary and sufficient condition for the existence of certain homomorphisms between mono-unary algebras. In this paper, an example is presented to show that Novotny's condition is not sufficient, and a slightly stronger condition is shown to be both necessary and sufficient. The techniques of the proof are essentially the same as those used by Novotny.
\end{abstract}

Before proceeding, a brief summary is given of the relevant definitions.

A mono-unary algebra ("algebra" for short) is a pair $(M, f)$ where $f$ is any self-map of the set $M$; a homomorphism from $(M, f)$ to $(N, g)$ is a map $F: M \rightarrow N$ such that $F \circ f=g \circ F$.

Given such an algebra $(M, f)$, let $f^{0}(x)=x$ for all $x \in M$, and $f^{n+1}(x)=f\left(f^{n}(x)\right)$ for all $n \in \omega$; then $[x]=\left\{f^{n}(x) \mid n \in \omega\right\}$ is the subalgebra generated by $x$. For $x, y \in M$, define $x \rho y$ iff $[x] \cap[y] \neq \varnothing$ (equivalently, $x \rho y$ iff $f^{m}(x)=f^{n}(y)$ for some $\left.m, n \in \omega\right)$. This defines a congruence $\rho$ on the algebra $(M, f)$, the blocks of which are called the connected components of $(M, f)$; if there is only one such component then the algebra is called connected. The connected components of $M$ are each subalgebras of $M$, and a map from $M$ into any algebra is a homomorphism iff its restriction to each connected component of $M$ is a homomorphism. For this reason we need only consider homomorphisms from connected algebras $M$.

For each $x \in M$, either $f^{m}(x)=f^{n}(x)$ for some $m \neq n$, in which case $[x]$ is finite, or $[x]$ is infinite. If $[x]$ is finite, let $L(x)$ be the smallest natural number $m$ with $f^{m}(x)=f^{m+k}(x)$ for some $k \neq 0$, and let $R(x)$ be the smallest natural number $k \neq 0$ with $f^{L(x)}(x)=f^{L(x)+k}(x)$. $\left(R(x)\right.$ is the "rank" as defined by Novotny.) Then $f^{m}(x)=f^{n}(x)$ for $m<n$ implies $L(x) \leqq m$ and $R(x) \mid n-m$. If [x] is infinite, define $L(x)=\infty$ and $R(x)=0$. (Here, and in the remainder of the paper, $\infty$ is defined to be greater than every ordinal number, and we will use the convention that 0 is divisible by every natural number.)

Now (as in Novotny) define sets $M_{\alpha} \subseteq M$. for ordinals $\alpha$ inductively as follows:

$$
\begin{aligned}
& M_{0}=\left\{x \in M \mid f^{-1}(x)=\varnothing\right\} \\
& M_{\alpha}=\left\{x \in M-\bigcup_{\lambda<\alpha} M_{\lambda} \mid f^{-1}(x) \subseteq \bigcup_{\lambda<\alpha} M_{\lambda}\right\} .
\end{aligned}
$$

Then the $M_{\alpha}$ are all pairwise disjoint, and for all $x \in M$, either 
$x \in M_{\alpha}$ for some $\alpha$, or there exist elements $x_{n} \in M$ for $n \in w$ with $x_{0}=x$ and $f\left(x_{n+1}\right)=x_{n}$ for all $x \in \omega$.

Define

$$
S(x)=\left\{\begin{array}{lll}
\alpha & \text { if } & x \in M_{\alpha} \\
\infty & \text { if } & x \notin \cup M_{\alpha} .
\end{array}\right.
$$

Note that $S(f(x)) \geqq S(x)+1$ (provided we define $\infty+1=\infty$ ).

Now suppose $(N, g)$ is also a mono-unary algebra, and that the sets $N_{\alpha} \subseteq N$ have been defined analogously to the $M_{\alpha}$, along with the corresponding function $S$.

THeOREM. For any $a \in M, b \in N$, if $M$ is connected then there is a homomorphism $F: M \rightarrow N$ with $F(a)=b$ iff $L(b) \leqq L(a), R(b) \mid R(a)$, and $S\left(f^{n}(a)\right) \leqq S\left(g^{n}(b)\right)$ for all $n \in \omega$.

Proof. If $F$ is a homomorphism from $(M, f)$ to $(N, g)$ with $F(a)=b$, and if $f^{m}(a)=f^{n}(a)$ then $g^{m}(b)=g^{m}(F(a))=F\left(f^{m}(a)\right)=$ $F\left(f^{n}(a)\right)=g^{n}(F(a))=g^{n}(b)$, and hence $L(b) \leqq L(a)$ and $R(b) \mid R(a)$. A straightforward induction on $\alpha$ shows that for all $x \in M$, if $F(x) \in$ $\bigcup_{\lambda<\alpha} N_{\lambda}$ then $x \in \bigcup_{\lambda<\alpha} M_{\lambda}$, and hence $S(x) \leqq S(F(x))$ for all $x \in M$, which yields $S\left(f^{n}(a)\right) \leqq S\left(g^{n}(b)\right)$ for all $n$.

Conversely, suppose $L(b) \leqq L(a), R(b) \mid R(a)$ and $S\left(f^{n}(a)\right) \leqq S\left(g^{n}(b)\right)$ for all $n \in \omega$. Define sets $X_{n} \subseteq M$ for $n \in \omega$ as follows:

$$
\begin{aligned}
X_{0} & =[a] \\
X_{n+1} & =\left\{x \in M-\bigcup_{i<n} X_{i} \mid f(x) \in X_{n}\right\} .
\end{aligned}
$$

Then the $X_{n}$ are pairwise disjoint, and since $M$ is connected, $\mathrm{U}_{n \in \omega} X_{n}=$ $M$. We define $F(x)$ for $x \in X_{n}$ by induction on $n$, in such a way that $S(x) \leqq S(F(x))$.

If $x \in X_{0}$ then $x=f^{m}(a)$ for some $m \in \omega$. If in addition $x=f^{n}(a)$ for $n>m$ then $L(a) \leqq m$ and $R(a) \mid n-m$, and so by hypothesis $L(b) \leqq m$ and $R(b) \mid n-m$, which implies $g^{m}(b)=g^{n}(b)$. Define $F(x)=$ $g^{m}(b)$; the preceding sentence shows that this is well-defined. Moreover, $S(x)=S\left(f^{m}(a)\right) \leqq S\left(g^{m}(b)\right)=S(F(x))$, as required.

If $x \in X_{n+1}$ then $f(x) \in X_{n}$ and so by inductive hypothesis, $F(f(x))$ is defined and $S(F(f(x))) \geqq S(f(x))$. Since $S(f(x)) \geqq S(x)+1$, this implies that $F(f(x)) \notin N_{\lambda}$ for any $\lambda \leqq S(x)$, and hence $g^{-1}(F(f(x))) \nsubseteq$ $\mathrm{U}_{\lambda<S(x)} N_{\lambda}$. For each $x \in X_{n+1}$, let $F(x)$ be any element of $g^{-1}(F(f(x)))$ $\mathrm{U}_{\lambda<S(x)} N_{\lambda}$; then $g(F(x))=F(f(x))$ and $S(F(x)) \geqq S(x)$.

Thus this yields a homomorphism $F:(M, f) \rightarrow(N, g)$ with $F(a)=$ $b$, as required.

CoRollary. If $M$ is connected and $a \in M, b \in N$ such that 
$R(b) \mid R(a)$ and $S\left(f^{n}(a)\right) \leqq S\left(g^{n}(b)\right)$ for all $u \in \omega$ then there is a homomorphism $F: M \rightarrow N$ with $F(a) \in[b]$.

Proof. Let $m=L(b)$; then $L\left(g^{m}(b)\right)=0$ and $R\left(g^{m}(b)\right)=R(b)$ and for all $n \in \omega, S\left(g^{n}(b)\right) \leqq S\left(g^{n+m}(b)\right)=S\left(g^{n}\left(g^{m}(b)\right)\right)$, and so by the theorem there is a homomorphism $F:(M, f) \rightarrow(N g)$ with $F(a)=g^{m}(b)$.

Novotny's Hauptsatz 2.14 claims that the above theorem is true without the restriction $L(b) \leqq L(a)$, but the following example shows that this is not the case. Let $M=\{a\}$ (so $f(a)=a$ ) and let $N=\omega$, $g(0)=0, g(n+1)=n$ for all $n$; then $R(a)=1$ and $S\left(f^{n}(a)\right)=\infty$ for all $n$. Also, for $b=1 \in N$, we have $R(b)=1$, and $S\left(g^{n}(b)=\infty\right.$ for each $n$. Clearly the map $F: M \rightarrow N$ with $F(a)=b$ is not a homomorphism, since $F(f(a))=b \neq 0=g(F(a))$.

\section{REFERENCE}

1. M. Novotny, Uber Abbildungen von Mengen, Pacific J. Math., 13 (1963), 1359-1369.

Received December 2, 1980 and in revised form May 21, 1981.

MCMASTER UNIVERSITY

HAMILTON, ONTARIO

CANADA L8S $4 \mathrm{~K} 1$ 



\title{
PACIFIC JOURNAL OF MATHEMATICS
}

\section{EDITORS}

\author{
DONALD BABBITT (Managing Editor) \\ University of California \\ Los Angeles, CA 90024 \\ Hugo RossI \\ University of Utah \\ Salt Lake City, UT 84112 \\ C. C. MOORE and Arthur Agus \\ University of California \\ Berkeley, CA 94720
}

\section{J. DugundjI}

Department of Mathematics

University of Southern California

Los Angeles, CA 90007

R. FinN and J. Milgram

Stanford University

Stanford, CA 94305

\section{ASSOCIATE EDITORS}
R. ARENS
E. F. BeCKENBACH
B. H. NeumanN
F. WOLF
K. YoshidA

\section{SUPPORTING INSTITUTIONS}

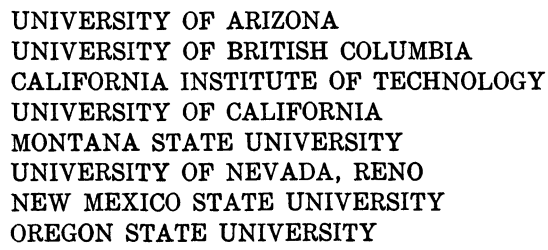

UNIVERSITY OF ARIZONA

UNIVERSITY OF BRITISH COLUMBIA

CALIFORNIA INSTITUTE OF TECHNOLOGY

UNIVERSITY OF CALIFORNIA

MONTANA STATE UNIVERSITY

UNIVERSITY OF NEVADA, RENO

NEW MEXICO STATE UNIVERSITY

OREGON STATE UNIVERSITY

\author{
UNIVERSITY OF OREGON \\ UNIVERSITY OF SOUTHERN CALIFORNIA \\ STANFORD UNIVERSITY \\ UNIVERSITY OF HAWAII \\ UNIVERSITY OF TOKYO \\ UNIVERSITY OF UTAH \\ WASHINGTON STATE UNIVERSITY \\ UNIVERSITY OF WASHINGTON
}

The Supporting Institutions listed above contribute to the cost of publication of this Journal, but they are not owners or publishers and have no responsibility for its content or policies.

Mathematical papers intended for publication in the Pacific Journal of Mathematics should be in typed form or offset-reproduced, (not dittoed), double spaced with large margins. Please do not use built up fractions in the text of the manuscript. However, you may use them in the displayed equations. Underline Greek letters in red, German in green, and script in blue. The first paragraph or two must be capable of being used separately as a synopsis of the entire paper. Please propose a heading for the odd numbered pages of less than 35 characters. Manuscripts, in triplicate, may be sent to any one of the editors. Please classify according to the scheme of Math. Reviews, Index to Vol. 39. Supply name and address of author to whom proofs should be sent. All other communications should be addressed to the managing editor, or Elaine Barth, University of California, Los Angeles, California, 90024.

50 reprints to each author are provided free for each article, only if page charges have been substantially paid. Additional copies may be obtained at cost in multiples of 50 .

The Pacific Journal of Mathematics is issued monthly as of January 1966. Regular subscription rate: $\$ 102.00$ a year (6 Vols., 12 issues). Special rate: $\$ 51.00$ a year to individual members of supporting institutions.

Subscriptions, orders for numbers issued in the last three calendar years, and changes of address shoud be sent to Pacific Journal of Mathematics, P.O. Box 969, Carmel Valley, CA 93924, U.S.A. Old back numbers obtainable from Kraus Periodicals Co., Route 100, Millwood, NY 10546.

\section{PUBLISHED BY PACIFIC JOURNAL OF MATHEMATICS, A NON-PROFIT CORPORATION}

Printed at Kokusai Bunken Insatsusha (International Academic Printing Co., Ltd.). 8-8, 3-chome, Takadanobaba, Shinjuku-ku, Tokyo 160, Japan. 


\section{Pacific Journal of Mathematics}

Vol. 99, No. $2 \quad$ June, 1982

Thomas E. Armstrong and Karel Libor Prikry, On the semimetric on a

Boolean algebra induced by a finitely additive probability measure . . . .249

Walter Russell Bloom, Strict local inclusion results between spaces of

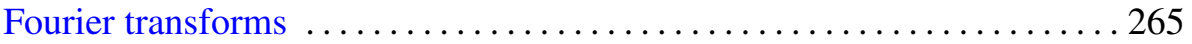

Richard Clark Brown, Notes on generalized boundary value problems in

Banach spaces. II. Infinite-dimensional extension theory ........... 271

Sui Sun Cheng, Isoperimetric eigenvalue problem of even order differential

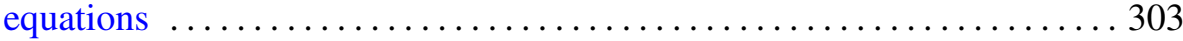

Lung O. Chung and Jiang Luh, Derivations of higher order and

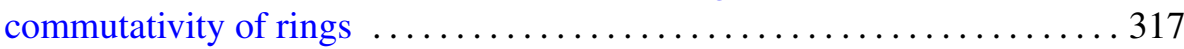

Ali Ahmad Fora, A fixed point theorem for product spaces . . . . . . . . . 327

Barry J. Gardner, Radical classes of regular rings with Artinian primitive

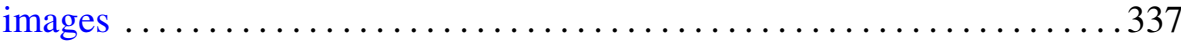

John Brady Garnett and Peter Wilcox Jones, BMO from dyadic BMO . . . 351

Allen E. Hatcher, On the boundary curves of incompressible surfaces . . . . 373

Richard Howard Hudson and Kenneth S. Williams, Resolution of

ambiguities in the evaluation of cubic and quartic Jacobsthal sums .....379

Viktor Losert, Counter-examples to some conjectures about doubly

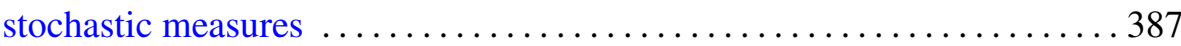

Kenneth Derwood Magill, Jr., P. R. Misra and Udai Bhan Tewari,

Structure spaces for sandwich semigroups

Mark Mandelker, Continuity of monotone functions

Kenneth Guy Miller, An index theorem and hypoellipticity on nilpotent Lie groups ......................................... 419

Evelyn M. Nelson, Homomorphisms of mono-unary algebras . . . . . . . . . 427

Marvin E. Ortel, The support of an extremal dilatation . . .

R. S. Pathak and O. P. Singh, Finite Hankel transforms of distributions . . . 439

Richard Cole Penney, The theory of ad-associative Lie algebras

Linda Ruth Sons, Zero distribution of functions with slow or moderate

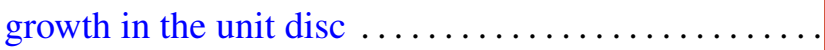

Russell Bruce Walker, Transversals to laminations 